\title{
Expanding the Reach of Research: Quantitative Evaluation of a Web-Based Approach for Remote Recruitment of People Who Hear Voices
}

Benjamin Buck ${ }^{1}$, PhD; Ayesha Chander ${ }^{1}$, MRes; Rachel M Brian ${ }^{1}$, MPH; Weichen Wang ${ }^{2}$, ME; Andrew T Campbell ${ }^{2}$, PhD; Dror Ben-Zeev ${ }^{1}$, PhD

\footnotetext{
${ }^{1}$ Behavioral Research in Technology and Engineering (BRiTE) Center, Department of Psychiatry and Behavioral Sciences, University of Washington, Seattle, WA, United States

${ }^{2}$ Department of Computer Science, Dartmouth College, Hanover, NH, United States
}

\section{Corresponding Author:}

Benjamin Buck, PhD

Behavioral Research in Technology and Engineering (BRiTE) Center

Department of Psychiatry and Behavioral Sciences

University of Washington

1959 NE Pacific Street

Seattle, WA, 98195

United States

Phone: 12062218518

Email: buckbe@uw.edu

\section{Abstract}

Background: Similar to other populations with highly stigmatized medical or psychiatric conditions, people who hear voices (ie, experience auditory verbal hallucinations $[\mathrm{AVH}]$ ) are often difficult to identify and reach for research. Technology-assisted remote research strategies reduce barriers to research recruitment; however, few studies have reported on the efficiency and effectiveness of these approaches.

Objective: This study introduces and evaluates the efficacy of technology-assisted remote research designed for people who experience AVH.

Methods: Our group developed an integrated, automated and human complementary web-based recruitment and enrollment apparatus that incorporated Google Ads, web-based screening, identification verification, hybrid automation, and interaction with live staff. We examined the efficacy of that apparatus by examining the number of web-based advertisement impressions (ie, number of times the web-based advertisement was viewed); clicks on that advertisement; engagement with web-based research materials; and the extent to which it succeeded in representing a broad sample of individuals with AVH, assessed through the self-reported AVH symptom severity and demographic representativeness (relative to the US population) of the sample recruited.

Results: Over an 18-month period, our Google Ads advertisement was viewed 872,496 times and clicked on 11,183 times. A total amount of US $\$ 4429.25$ was spent on Google Ads, resulting in 772 individuals who experience AVH providing consent to participate in an entirely remote research study (US $\$ 0.40$ per click on the advertisement and US $\$ 5.73$ per consented participant) after verifying their phone number, passing a competency screening questionnaire, and providing consent. These participants reported high levels of AVH frequency (666/756, 88.1\% daily or more), distress $(689 / 755,91.3 \%)$, and functional interference $(697 / 755,92.4 \%)$. They also represented a broad sample of diversity that mirrored the US population demographics. Approximately one-third $(264 / 756,34.9 \%)$ of the participants had never received treatment for their AVH and, therefore, were unlikely to be identified via traditional clinic-based research recruitment strategies.

Conclusions: Web-based procedures allow for time saving, cost-efficient, and representative recruitment of individuals with $\mathrm{AVH}$ and can serve as a model for future studies focusing on hard-to-reach populations.

(JMIR Form Res 2021;5(6):e23118) doi: $10.2196 / 23118$

\section{KEYWORDS}

digital health; research procedures; recruitment; mobile phone 


\section{Introduction}

\section{Background}

Auditory verbal hallucinations (AVH; or voices), or erroneous perceptions of speech, are a hallmark symptom of schizophrenia spectrum disorders (SSDs). They are experienced by $5 \%$ to $28 \%$ of the general population [1-4], including many people with a range of psychiatric diagnoses as well as many people who are otherwise considered healthy. In their most severe form, AVH are linked to anxiety, depression, and functional impairment [5,6]. AVH present unique challenges for research. First, individuals with SSDs who hear voices are considered a hard-to-reach population or a group that faces geographical, social, or economic barriers to participation [7,8]. SSDs are overrepresented in economically deprived and socially isolated groups [9,10], and treatment resources for them are scarce [11]. Many have no contact with mental health providers [12-14]. Others are reluctant to engage with the mental health system because of concerns about stigma [15], disagreement with diagnosis [16,17], or negative attitudes toward services [18]. Second, common clinical research practices often fail to access individuals with less severe or non-clinical AVH. Most individuals with AVH do not meet the criteria for an SSD; they often present with a range of diagnoses, including major depressive disorder, bipolar disorder, or may have never received a diagnosis at all $[19,20]$. Due to their reduced impact and increased independent coping skills, individuals with nonclinical AVH may be less likely to engage in research through traditional clinical settings. They may also opt against self-identifying because of concerns about stigma [21].

Digital technologies may help address these barriers. The average American adult is estimated to spend 3 hours and 48 minutes per day on a smartphone, tablet, or computer, with the majority of that time (62\%) spent on the internet and using an app on a smartphone [22]. More than 1 in 3 adults report that they have gone on the internet to better understand a health condition [23]. Although smartphone ownership tends to lag behind the general population, many individuals with serious mental illnesses report owning a smartphone [24], and this number has rapidly increased over the past two decades [25]. Individuals with SSDs report similar levels of health-related internet and web-based engagement [26] and are willing to engage in a variety of research or clinical activities on the web, including assessments [27,28], interventions [29-31], and peer communication [32,33]. Web-based approaches allow participants to covertly self-identify and thus could reduce the impact of stigma on research participation [34]. Furthermore, the COVID-19 pandemic has revealed additional vulnerabilities in in-person research recruitment procedures. During the pandemic, many of these activities have halted; however, research engagement through digital technology can continue while remaining adherent to physical distancing guidelines.

One particularly promising approach to address these issues is the use of technology-assisted remote research. This term describes a constellation of web-based tools (eg, advertisements posted in search engine results and email listservs) that require no face-to-face interactions with prospective participants and thus obviate many of the barriers common in traditional research. These differ from traditional recruitment methodologies that require partnerships with partner organizations with brick-and-mortar locations or other recruitment tools such as flyers. These efficient and cost-effective $[35,36]$ tools have been used to recruit research participants from several psychiatric populations, including people with depression [35], bipolar disorder [36], and suicidality [37]. These tools may be specifically well suited to address the extant challenges in recruiting and engaging individuals who experience AVH. As it is not situated within a health care system, technology-assisted remote research may be less susceptible to overrepresenting individuals engaged in treatment. It also potentially removes economic and social barriers faced by hard-to-reach populations (eg, time constraints and travel time) and allows for anonymous participation, thus reducing the impact of stigma.

Web-based methodologies are not without challenges. Research has examined the extent to which web-based research participants (eg, users of web-based platforms such as Amazon Mechanical Turk) are representative of the general population [38-40]. Others have raised concerns about participants' gaming or earning payments without honest and effortful participation [41]. For example, participants may attempt to complete web-based studies multiple times by masking their identifiers (eg, name and email address). Few studies have presented methods and models to engage difficult-to-reach populations while preserving the security, privacy, and validity of research data.

\section{Objectives}

In this paper, we report on the use of a technology-assisted remote research approach designed to recruit people who experience AVH. These procedures combine public-facing technologies (eg, Google Ads) with automated digital tools (eg, coding scripts to filter prospective participants) and available remote human support to efficiently recruit a difficult-to-reach population while preserving data security and quality. We describe the structure of that system and report several metrics assessing its performance, including (1) the number of web-based advertisement impressions (ie, number of times the web-based advertisement was viewed); (2) clicks on that advertisement; (3) engagement with web-based research materials; and (4) the extent to which it succeeded at representing a broad sample of individuals with AVH, assessed through self-reported AVH symptom severity and demographic representativeness (relative to the US population) of the sample recruited.

\section{Methods}

\section{Overview}

These digital tools were built for a primary study described elsewhere examining the real-time, real-place phenomenology of AVH [42]. This involved downloading and carrying a smartphone app for a 30-day study period that deployed brief ecological momentary assessment questionnaires and captured data through smartphone sensors. Study inclusion criteria included speaking English, being 18 years or older, living in 
the United States, experiencing AVH at least once per week, and ownership of an Android smartphone. Exclusion criteria included previous participation in the study and being unavailable for 30 days of consecutive data collection. The internal review boards at the University of Washington and Dartmouth College approved all the study procedures.

\section{Google Ads and Keywords}

To recruit individuals reporting AVH, we used Google Ads, a system of web-based advertisements wherein advertisements are viewable by individuals who use terms that match preselected keywords provided by the advertiser. Advertisements are designed to resemble a typical Google search result and thus comprise a title, URL, and brief description. In addition to keywords, the system allows for the entry of negative keywords, which function in the opposite way, ensuring that the advertisements are not viewable by individuals who search one of the negative keywords. Google Ads records the number of impressions, keywords used, number of clicks linked to the landing page and cost per click, and basic demographics of those who clicked on the advertisement (eg, age, gender, and household income, if reported to Google by the user). For this study, we selected keywords based on several sources: qualitative responses during our early work [43] as well as a rapid review of the academic literature, consultation with researchers focused on serious mental illness, and a review of blogs of people with lived experience. These keywords included descriptors that involved both clinical language (eg, schizophrenia and bipolar disorder) and nontraditional appraisals of AVH or related terms (eg, talking to ghosts and going crazy). Positive keywords were allowed to have a broad match with search terms, according to which search terms could be reordered or accompanied with other terms. Negative keywords were entered with a phrase match setting, according to which the exact phrase must be included in the search for the user to be blocked. Negative keywords were selected to prevent individuals from attempting to complete the study a second time (eg, hearing voice research and bipolar studies that pay).

\section{Web-Based Recruitment Materials}

Once users clicked on the advertisement, they were taken to the study landing page that provided written and video descriptions of the study. The consent form was available for download on this page. Participants were instructed to click on a "see if I am eligible" button if they were interested; this button then triggered a pop-up message requesting their email and a valid mobile phone number. This number received a text message with a code that prospective participants had to enter on the study website to gain access to the eligibility questionnaire. Once found eligible, participants were again given access to the consent form to download and review and asked to answer all competency questions correctly within 3 attempts. Participants were excluded if they were unable to complete this step successfully, as they were deemed unable to provide informed consent. Participants were also excluded if they had previously participated in the study. Therefore, the server ran the email and phone numbers provided through the participant database and automatically blocked people with repeat phone numbers from continuing the enrollment process. If participants met eligibility criteria via the screening questions and provided informed consent, their participation in the study officially began (ie, access to baseline assessments and the study app was provided). If at any point their responses indicated that they were ineligible (eg, 3 failed attempts to answer competency questions or previous participation), they were taken to a page where they were thanked for their interest but informed that they were ineligible to participate. Throughout this process, a staff member was available by phone and email for participants to call if the prospective participant faced barriers or had questions. Figure 1 provides an overview of the flow of interested individuals from the landing page to the consent and initiation of the study. 
Figure 1. Participant flow and attrition at each stage of the web-based engagement procedure.

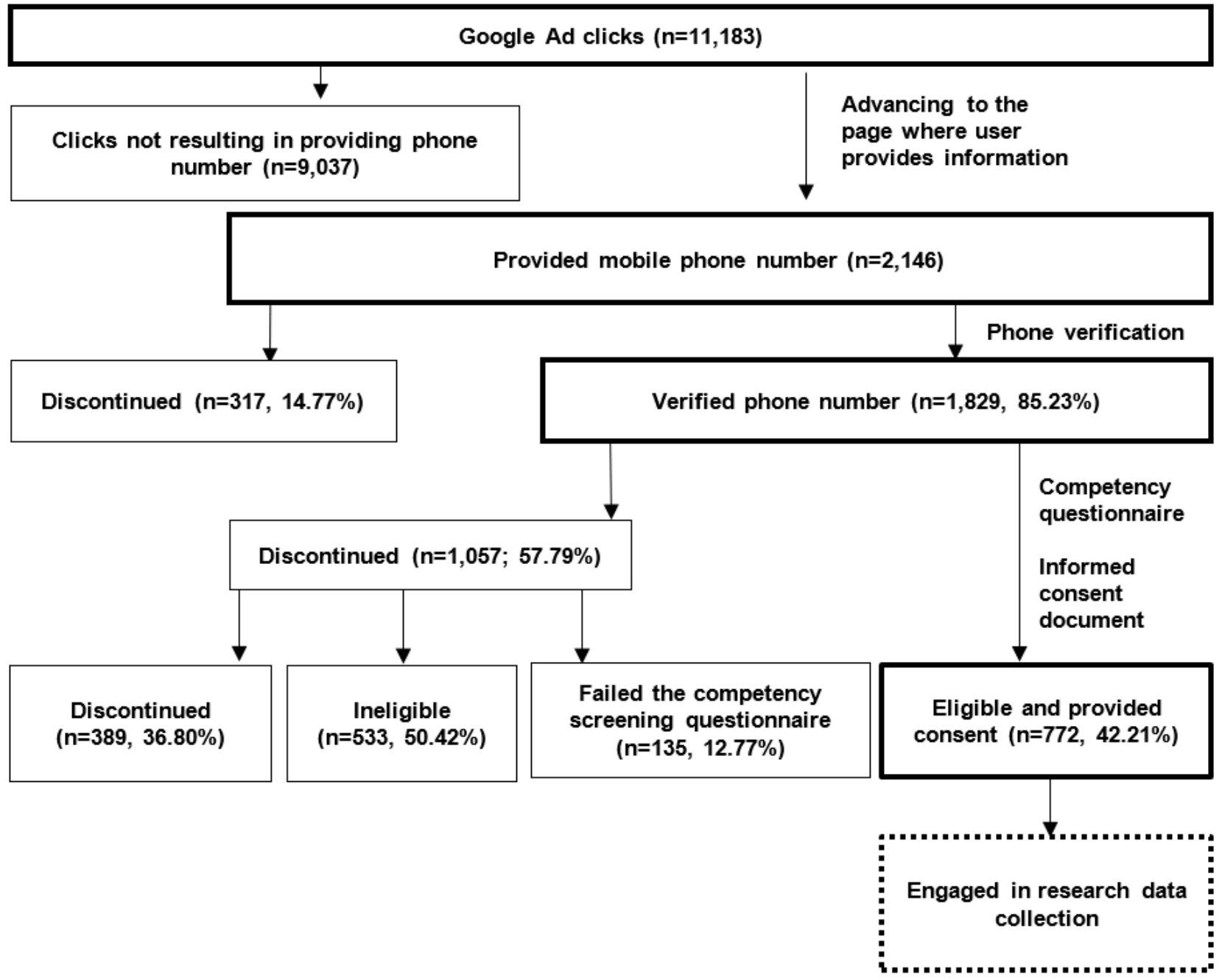

\section{Data Security and Validity Procedures}

In addition to the phone verification process, other procedures were also used to deter gamers or participants aiming to earn payments through duplicate or otherwise dishonest participation. These involved identifying prospective participants based on suspicious digital activity; when such users were identified, a research coordinator contacted them to conduct additional live screening by telephone. We identified this suspicious activity by (1) reviewing their means of access to the study landing page and (2) assessing duplicate emails, phone numbers, and email addresses. First, as a user cannot ensure that a Google Ad will appear in their search terms, it was expected that gamers would attempt to access the study landing page by entering the study URL directly, as opposed to honest participants who would only respond to the link listed in Google Ads. Thus, different links distinguished those who accessed the page via Google Ads versus those who accessed it directly. When a direct arrival initiated the screening process, a research coordinator would receive a notification and conduct additional screening of the prospective participant by phone; they were only allowed to proceed if cleared by the research coordinator. Second, the research coordinator would also receive an automated email if a participant attempted to enter the study with (1) an identical IP (internet protocol) address to a previous participant or (2) an email address for which characters matched the email of a previously enrolled participant by $>90 \%$. The study responses of these suspicious participants were reviewed on an ongoing basis (ie, identifiers and patterns in survey responses) and discussed at subsequent team meetings to determine whether additional screening was warranted by these patterns of responses. Participants were discontinued from the study if it was determined after additional screening that they were attempting to participate in the study for a second time $(n=44)$ or were otherwise dishonest about their eligibility $(n=2)$. No adverse events occurred throughout the course of the study.

\section{Results}

\section{Overview}

The aim of this study is to examine the efficiency and effectiveness of web-based recruitment of individuals who experience $\mathrm{AVH}$, according to a number of metrics, including (1) the number of web-based advertisement impressions (ie, number of times it was viewed) and clicks; (2) engagement with web-based research materials (ie, whether and how participants enrolled); and (3) the extent to which it succeeded in representing a broad sample of individuals with AVH, assessed through self-reported AVH symptom severity and demographic representativeness (relative to the US population). 


\section{Advertisement Impressions and Clicks}

Advertisements were posted from February 2018 to September 2019 , with a total budget of US $\$ 4429.25$. The advertisement was viewed 872,496 times and was clicked on 11,183 times, reaching a click-through rate (clicks per impression) of $1.28 \%$ at an average cost of US $\$ 0.40$ per click. The cost of a successfully recruited participant, that is, one who completed the screening processes and informed consent portions completely, was US $\$ 5.74$ per person. The top 5 advertisement keywords were mental illness, schizophrenia, mental health, bipolar, and hear voices. Table 1 presents the number of impressions, clicks, click-through rate, and cost per click by advertisement keyword. Of the individuals who clicked on the advertisement and had available demographic information, most (9896/11,223, 88.18\%) clicked on the advertisement through mobile phones, whereas few used desktop computers $(700 / 11,223,6.24 \%)$ or tablets $(627 / 11,223,5.59 \%)$.

Table 1. Measures of advertisement engagement for all keywords included to reach people who hear voices ${ }^{\mathrm{a}}$.

\begin{tabular}{|c|c|c|c|c|c|}
\hline Keywords & Impressions $^{\mathrm{b}}, \mathrm{n}$ & Clicks, $\mathrm{n}$ & Click-through rate (\%) & Average cost per click (US \$) & Total cost (US \$) \\
\hline Mental illness & 188,766 & 2263 & 1.20 & 0.42 & 951.33 \\
\hline Schizophrenia & 97,872 & 1945 & 1.99 & 0.41 & 794.19 \\
\hline Mental health & 146,438 & 1753 & 1.20 & 0.43 & 757.05 \\
\hline Bipolar & 82,815 & 931 & 1.12 & 0.44 & 410.64 \\
\hline Hear voices & 59,321 & 881 & 1.49 & 0.33 & 294.16 \\
\hline I hear voices & 55,629 & 815 & 1.47 & 0.35 & 286.64 \\
\hline Hearing sounds & 47,702 & 610 & 1.28 & 0.37 & 226.86 \\
\hline Hearing voices in head & 22,234 & 445 & 2.00 & 0.34 & 151.06 \\
\hline Mental illness hearing voices & 19,685 & 422 & 2.14 & 0.35 & 148.30 \\
\hline Schizoaffective & 8787 & 181 & 2.06 & 0.39 & 70.28 \\
\hline Hearing voices disorder & 9972 & 175 & 1.75 & 0.39 & 67.77 \\
\hline Auditory hallucinations & 6479 & 158 & 2.44 & 0.33 & 51.59 \\
\hline Hearing things & 39,836 & 148 & 0.37 & 0.33 & 48.90 \\
\hline Delusional & 22,321 & 130 & 0.58 & 0.33 & 42.88 \\
\hline Going crazy & 11,880 & 78 & 0.66 & 0.33 & 25.49 \\
\hline Talking to ghosts & 9904 & 67 & 0.68 & 0.37 & 24.96 \\
\hline Stress relief & 21,329 & 64 & 0.30 & 0.46 & 29.12 \\
\hline Spirits talking & 13,142 & 58 & 0.44 & 0.42 & 24.09 \\
\hline Musical ear syndrome & 3767 & 19 & 0.50 & 0.44 & 8.39 \\
\hline Am I crazy & 1644 & 19 & 1.16 & 0.31 & 5.95 \\
\hline Am I insane & 942 & 12 & 1.27 & 0.45 & 5.43 \\
\hline Disembodied voices & 227 & 3 & 1.32 & 0.28 & 0.84 \\
\hline I'm not crazy & 1591 & 3 & 0.19 & 0.39 & 1.18 \\
\hline Hearing voices $^{c}$ & 122 & 3 & 2.46 & 0.71 & 2.15 \\
\hline Voice hearing $^{\mathrm{c}}$ & 91 & 0 & 0 & 0 & 0 \\
\hline
\end{tabular}

${ }^{\mathrm{a}}$ The total number of impressions was 872,496 ; the total number of clicks was 11,183 ; average click-through rate was $1.28 \%$; average cost per click was US $\$ 0.40$; and the total cost was US $\$ 4429.25$.

${ }^{\mathrm{b}}$ An impression is counted each time the advertisement is shown on a search result page.

${ }^{\mathrm{c}}$ These keywords were included for only a portion of the study period because of concerns related to repeat study participants searching for and finding the study advertisement.

\section{Study Enrollment}

The flow of interested users from Google Ads through informed consent is shown in Figure 1. Of the 11,183 clicks on the study Google Ad, a total of 2146 individuals provided their mobile phone number to be verified for participation in the study. Of the 2146 participants who provided a phone number, 1829 $(85.23 \%)$ verified this phone number with a code. Of the 1829 individuals with a verified phone number, 772 (42.21\%) provided consent to participate in the study. Most individuals who verified their phone number but did not provide informed consent, did not meet the eligibility criteria $(533 / 1057,50.43 \%)$, 
whereas the remainder either failed a competency screening questionnaire $(135 / 1057,12.77 \%)$ or chose not to participate $(389 / 1057,36.8 \%)$.

\section{Participant AVH Frequency and Severity}

Results related to participants' AVH frequency and severity are presented in Table 2. Most individuals who provided consent to participate reported that they had sought treatment for their AVH at some point in their lifetime $(492 / 756,65.1 \%)$ but over one-third had not $(264 / 756,34.9 \%)$. The most common self-reported diagnoses were depression (488/749, 65.2\%), bipolar disorder $(352 / 749,47 \%)$, and posttraumatic stress disorder (328/749, 43.8\%). Most participants reported hearing voices at least once a day $(666 / 756,88.1 \%)$ and that the voices interfered with their daily activities in some way (697/755, $92.4 \%$ ), with almost half of the participants reporting "quite a bit" or "extreme" interference (346/755, 45.9\%). Most reported that the voices they hear are distressing $(689 / 755,91.3 \%)$ and more than half reported "quite a bit" or "extreme" distress $(416 / 755,55.1 \%)$. Participants varied in terms of how open they were about these voices with others. Most participants (443/756, $58.6 \%$ ) had shared their experience of voices with a medical professional. Approximately half of the participants had immediate family members $(376 / 755,49.8 \%)$ or a significant other $(350 / 754,46.4 \%)$ who knew about their experience of voices. One-tenth $(75 / 753,10 \%)$ of the sample reported that no one else knew about their experience of voices. These figures suggest that this remote recruitment strategy successfully engaged a broad continuum of people with AVH experiences, including individuals with significant and severe AVH as well as those who had never engaged in treatment for them. 
Table 2. Participants' diagnoses, experience, frequency, severity, and behavioral interference of auditory verbal hallucinations.

\begin{tabular}{ll}
\hline Clinical characteristics & Participants, $\mathrm{n}(\%)$
\end{tabular}

Lifetime treatment seeking $(\mathrm{n}=\mathbf{7 5 6})$

Yes

$492(65.1)$

No

$264(34.9)$

Self-reported diagnosis ${ }^{\mathrm{a}}$

Alzheimer or Parkinson disease ( $\mathrm{n}=747)$

Bipolar disorder $(\mathrm{n}=749)$

$352(47.0)$

Depression $(\mathrm{n}=749)$

$488(65.2)$

Traumatic brain injury $(\mathrm{n}=746)$

$50(6.7)$

Migraines ( $\mathrm{n}=747)$

$141(18.9)$

Schizoaffective disorder $(n=748)$

$210(28.1)$

Schizophrenia $(\mathrm{n}=749)$

$208(27.8)$

Posttraumatic stress disorder $(\mathrm{n}=749)$

$328(43.8)$

Substance use $(n=747)$

$228(30.5)$

Seizures $(n=748)$

None of the above $(n=749)$

$61(8.1)$

Other $(\mathrm{n}=772)$

87 (11.3)

Who knows about your voices? ${ }^{\mathrm{a}}$

No one knows $(n=753)$

People you know online but not in person $(n=756)$

Medical professionals/primary doctor/therapist $(n=756)$

443 (58.6)

Significant other (ie, boyfriend, girlfriend, or spouse) $(n=754)$

$350(46.4)$

Some of my friends $(\mathrm{n}=756)$

$333(44.0)$

All my friends $(\mathrm{n}=755)$

$83(11.0)$

Extended family $(\mathrm{n}=756)$

$105(13.9)$

Immediate family $(\mathrm{n}=755)$

$376(49.8)$

How frequently do you hear a voice or voices? $(n=756)$

No voices

Less than once day

Once or twice a day

Several times a day

All the time/constantly

How much do the voices interfere with your daily activities? $(n=755)$

No interference

A little bit

$162(21.5)$

Moderately

$189(25.0)$

Quite a bit

$187(24.8)$

Extremely interfering

How distressing are the voices that you hear? $(n=755)$

No voices are distressing me

A little bit 


\begin{tabular}{cl}
\hline Clinical characteristics & Participants, $\mathrm{n}(\%)$ \\
\hline Quite a bit & $205(27.2)$ \\
Extremely distressing & $211(27.9)$ \\
\hline
\end{tabular}

${ }^{\mathrm{a} P a r t i c i p a n t s ~ c o u l d ~ s e l e c t ~ m u l t i p l e ~ o p t i o n s . ~}$

\section{Participant Demographics and Representativeness}

The demographics of the study sample (Table 3) broadly reflect a number of US population trends. The average age of consented participants was 38.14 years (SD 9.86), which closely mirrored the median US age of 38.2 years [44]. In comparison with population estimates, the sample of individuals providing consent included larger percentages of multiple populations that are traditionally underrepresented in research, including Black or African American participants (108/760, 14.2\% in our study, estimated at $12.7 \%$ of the US population [45]), multiracial participants (90/760, $11.8 \%$ vs $3.4 \%$ of the US population [45]), sexual minorities $(156 / 766,20.3 \%$ gay, lesbian, or bisexual vs $5 \%$ [46]; 12/771, $1.6 \%$ transgender vs $0.6 \%$ [47]), and the homeless $(69 / 767,9.0 \%$ vs $0.2 \%$ [48]). Other groups appeared underrepresented relative to the general population, including individuals who identified as Asian (9/760, 1.2\% vs 5.6\% [45]), Hispanic or Latino (101/765, $13.2 \%$ vs $18.3 \%$ [45]), and male (292/771, 37.9\% vs $49.2 \%$ [45]).

Table 3. Demographics of participants who provided consent to participate.

\begin{tabular}{|c|c|}
\hline Demographic characteristic & Values \\
\hline Age (years; n=768), mean (SD) & $38.14(9.86)$ \\
\hline \multicolumn{2}{|l|}{ Sex or gender $(n=771), n(\%)$} \\
\hline Female & $470(61.0)$ \\
\hline Male & $286(37.1)$ \\
\hline Transgender & $12(1.6)$ \\
\hline Transgender woman & $6(0.8)$ \\
\hline Transgender man & $6(0.8)$ \\
\hline Other & $3(0.4)$ \\
\hline \multicolumn{2}{|l|}{ Race $(n=760), n(\%)$} \\
\hline White & $537(70.7)$ \\
\hline Black or African American & $108(14.2)$ \\
\hline Pacific Islander & $2(0.3)$ \\
\hline American Indian or Alaskan Native & $14(1.8)$ \\
\hline Asian & $9(1.2)$ \\
\hline More than one race & $90(11.8)$ \\
\hline \multicolumn{2}{|l|}{ Hispanic $(n=765), n(\%)$} \\
\hline Yes & $101(13.2)$ \\
\hline No & $664(86.8)$ \\
\hline \multicolumn{2}{|l|}{ Sexual orientation $(n=766), n(\%)$} \\
\hline Heterosexual or straight & $591(77.2)$ \\
\hline Gay or lesbian & $50(6.5)$ \\
\hline Bisexual & $106(13.8)$ \\
\hline Other & $19(2.5)$ \\
\hline \multicolumn{2}{|l|}{ Housing status $(\mathrm{n}=767), \mathrm{n}(\%)$} \\
\hline Independent or living on my own & $348(45.4)$ \\
\hline Living with family & $313(40.8)$ \\
\hline Assisted or supported living & $33(4.3)$ \\
\hline Substance treatment institution & $4(0.5)$ \\
\hline Homeless & $69(9.0)$ \\
\hline
\end{tabular}




\section{Discussion}

\section{Principal Findings}

Digital technologies are rapidly reshaping mental health research and services. One particular benefit of these approaches is their capacity to increase the reach of research to underserved populations. Previous work has demonstrated the potential of web-based engagement to facilitate help seeking among individuals at risk for psychosis by linking them to web-based resources about symptoms and treatments (eg, the Strong365 campaign [49]). This study builds on this earlier work by demonstrating that web-based tools can remotely facilitate research participation of individuals with psychotic symptoms at both clinical and nonclinical levels. The recruited sample reported clinically significant experiences with voices that were frequent, distressing, and functionally interfering, and over one-third had never received treatment for them. Overall, the results suggest that these web-based procedures allow for the efficient, affordable, and representative recruitment of research participants without reliance on a clinical setting.

Web-based digital recruitment methods compare favorably with extant approaches for engaging hard-to-reach populations in several ways. First, such methods appear to reduce costs. Traditional recruitment methods incur several costs in the process of raising interest and awareness of a study, such as increased staff time, flyers, mailings, and presentations to clinical or educational facilities [50]. These needs are obviated through remote recruitment. Our web-based advertisements were viewed by over 870,000 individuals for 18 months for less than US \$4500, a fraction of the cost that such exposure would necessitate using offline approaches. The approach of this study appeared to reduce costs relative to previous work using social media to recruit individuals with psychotic experiences [43]. Second, beyond increasing efficiency, these methods may improve representative sampling when the members of a group face barriers to participation. Research in other health-related populations has demonstrated that digital technologies may address these barriers $[7,8,51]$, in particular, accessing broader geographic regions [52,53] and more diverse respondents $[35,54]$. This study provides support for these benefits and suggests that they may also reduce barriers specific to individuals on either end of the continuum of AVH severity. Individuals with psychosis are difficult to engage in clinical research, given social isolation and economic hardship $[10,12,13]$. Those with undiagnosed and untreated AVH may be even more difficult to engage, given a lack of contact with typical clinical research settings as well as potential concerns about self-identifying with stigmatized experiences. This approach appeared to engage participants from both ends of this continuum; one-third of the participants reported never seeking treatment for their voices, a similar proportion reported that they experienced highly distressing voices daily. This finding also provides additional support for the utility of these approaches to engage individuals at risk either in programs that encourage help seeking $[49,55]$ or in remotely delivered interventions [33]. Although a few examples provide support for the feasibility of these initiatives, future work should examine remote treatment-seeking support and intervention for the psychosis continuum at a population level. Furthermore, notable in these data were the number of participants who were also members of other underrepresented populations, including racial minorities, sexual minorities, and the homeless. Although it remains an open question why these groups are better represented using these methods, it is possible that web-based engagement reduces barriers for underrepresented groups that may face additional intersectional experiences of stigma on top of those related to their mental health concerns alone.

\section{Limitations}

This study had some limitations. Although web-based methods may ameliorate some recruitment biases, they may worsen others. Web-based recruitment strategies rely on participants' ownership and adeptness to use technology to engage. Individuals who lack either may struggle to engage in these new avenues. This may be particularly pronounced among individuals who face economic barriers to several needed services. Most visitors to the research study landing page did not provide informed consent to participate. Specific factors may predict a lack of willingness to persist through automated screening steps (eg, persecutory ideation and cognitive functioning). If this is the case, this could limit the representativeness of the sample. Although our approach successfully engaged members of several typically underrepresented groups, others accounted for smaller proportions than their proportion of the US population, including Hispanic and Asian individuals. The prevalence of AVH in specific racial or ethnic groups is not clear in the academic literature at present; thus, it is not clear from these data whether overrepresentation of these groups relative to population demographic estimates is the result of a greater prevalence of $\mathrm{AVH}$ in specific groups, characteristics of our recruitment strategies, or other causes. Overall, however, our results suggest that web-based recruitment methods engage a diverse sample of individuals with AVH experiences.

\section{Conclusions}

Technology-assisted remote research procedures address several barriers that are common in traditional research. Engaging prospective participants outside of typical clinical settings removes existing sampling biases, allowing for greater representation of psychiatric populations. These procedures have also been able to continue despite the halted in-person research activities in light of social distancing measures imposed by the COVID-19 pandemic. This expansion of access and reach has been a principal contribution of digital health technologies, and health care institutions have only just begun to witness their potential impact [56]. Just as digital technologies create considerable opportunities for treatment engagement, such tools can also enhance clinical research. 


\section{Acknowledgments}

This study was supported by a grant from the National Institute of Mental Health (R01MH112641). BB is supported by a Mentored Patient-Oriented Research Career Development Award from the National Institute of Mental Health (K23MH122504).

\section{Conflicts of Interest}

DBZ has an intervention content licensing agreement with Pear Therapeutics and has financial interest in FOCUS technology. He has consulted for Trusst Health Inc, eQuility, and Otsuka Pharmaceuticals Ltd. The other authors have no conflicts of interest to disclose.

\section{References}

1. Tien AY. Distribution of hallucinations in the population. Soc Psychiatry Psychiatr Epidemiol 1991;26(6):287-292. [doi: 10.1007/bf00789221]

2. Scott J, Chant D, Andrews G, McGrath J. Psychotic-like experiences in the general community: the correlates of CIDI psychosis screen items in an Australian sample. Psychol Med 2005 Nov 23;36(2):231-238. [doi: 10.1017/s0033291705006392]

3. Johns LC, Cannon M, Singleton N, Murray RM, Farrell M, Brugha T, et al. Prevalence and correlates of self-reported psychotic symptoms in the British population. Br J Psychiatry 2004 Oct 02;185(4):298-305. [doi: 10.1192/bjp.185.4.298] [Medline: 15458989$]$

4. Johns LC, Nazroo JY, Bebbington P, Kuipers E. Occurrence of hallucinatory experiences in a community sample and ethnic variations. Br J Psychiatry 2002 Feb 02;180(2):174-178. [doi: 10.1192/bjp.180.2.174] [Medline: 11823331]

5. Hoffman R, Varanko M, Gilmore J, Mishara A. Experiential features used by patients with schizophrenia to differentiate 'voices' from ordinary verbal thought. Psychol Med 2007 Nov 30;38(8):1167-1176. [doi: 10.1017/s0033291707002395]

6. Freeman D, Garety PA. Connecting neurosis and psychosis: the direct influence of emotion on delusions and hallucinations. Behav Res Ther 2003 Aug;41(8):923-947. [doi: 10.1016/s0005-7967(02)00104-3]

7. Shaghaghi A, Bhopal R, Sheikh A. Approaches to recruiting 'hard-to-reach' populations into re-search: a review of the literature. Heal Promot Perspect 2011 Dec 20;1(2):86-94. [doi: 10.5681/hpp.2011.009]

8. Atkinson R, Flint J. Accessing hidden and hard-to-reach populations: snowball research strategies. Social Research Update. 2001. URL: https://www.researchgate.net/publication/ 46214232 Accessing Hidden and Hard-to-Reach Populations Snowball Research Strategies/link/ 5540f43a0cf2322227314d32/download [accessed 2021-05-26]

9. Richardson L, Hameed Y, Perez J, Jones PB, Kirkbride JB. Association of environment with the risk of developing psychotic disorders in rural populations: findings from the social epidemiology of psychoses in East Anglia study. JAMA Psychiatry 2018 Jan 01;75(1):75-83 [FREE Full text] [doi: 10.1001/jamapsychiatry.2017.3582] [Medline: 29188295]

10. McGrath J, Saha S, Welham J, El Saadi O, MacCauley C, Chant D. A systematic review of the incidence of schizophrenia: the distribution of rates and the influence of sex, urbanicity, migrant status and methodology. BMC Med 2004 Apr 28;2:13 [FREE Full text] [doi: 10.1186/1741-7015-2-13] [Medline: 15115547]

11. Saxena S, Thornicroft G, Knapp M, Whiteford H. Resources for mental health: scarcity, inequity, and inefficiency. Lancet 2007 Sep;370(9590):878-889. [doi: 10.1016/s0140-6736(07)61239-2]

12. Schoenbaum M, Sutherland JM, Chappel A, Azrin S, Goldstein AB, Rupp A, et al. Twelve-month health care use and mortality in commercially insured young people with incident psychosis in the United States. Schizophr Bull 2017 Oct 21;43(6):1262-1272 [FREE Full text] [doi: 10.1093/schbul/sbx009] [Medline: 28398566]

13. Mojtabai R, Fochtmann L, Chang S, Kotov R, Craig TJ, Bromet E. Unmet need for mental health care in schizophrenia: an overview of literature and new data from a first-admission study. Schizophr Bull 2009 Jul;35(4):679-695 [FREE Full text] [doi: 10.1093/schbul/sbp045] [Medline: 19505994]

14. Doyle R, Turner N, Fanning F, Brennan D, Renwick L, Lawlor E, et al. First-episode psychosis and disengagement from treatment: a systematic review. Psychiatr Serv 2014 May 01;65(5):603-611. [doi: 10.1176/appi.ps.201200570] [Medline: 24535333]

15. Fung KM, Tsang HW, Corrigan PW. Self-stigma of people with schizophrenia as predictor of their adherence to psychosocial treatment. Psychiatr Rehabil J 2008;32(2):95-104. [doi: 10.2975/32.2.2008.95.104] [Medline: 18840563]

16. Lincoln TM, Rief W, Westermann S, Ziegler M, Kesting M, Heibach E, et al. Who stays, who benefits? Predicting dropout and change in cognitive behaviour therapy for psychosis. Psychiatry Res 2014 May 15;216(2):198-205. [doi: 10.1016/j.psychres.2014.02.012] [Medline: 24602992]

17. Tait L, Birchwood M, Trower P. Predicting engagement with services for psychosis: insight, symptoms and recovery style. Br J Psychiatry 2003 Feb 02;182(2):123-128. [doi: 10.1192/bjp.182.2.123] [Medline: 12562739]

18. Schimmelmann BG, Conus P, Schacht M, Mc G, Lambert M. Predictors of service disengagement in first-admitted adolescents with psychosis. J Am Acad Child Adolesc Psychiatry 2006 Aug;45(8):990-999. [doi: 10.1097/01.chi.0000223015.29530.65] [Medline: 16865042]

19. van Os J, Hanssen M, Bijl RV, Ravelli A. Strauss (1969) revisited: a psychosis continuum in the general population? Schizophr Res 2000 Sep 29;45(1-2):11-20. [doi: 10.1016/S0920-9964(99)00224-8] 
20. van Os J, Linscott RJ, Myin-Germeys I, Delespaul P, Krabbendam L. A systematic review and meta-analysis of the psychosis continuum: evidence for a psychosis proneness-persistence-impairment model of psychotic disorder. Psychol Med 2009 Feb;39(2):179-195. [doi: 10.1017/S0033291708003814] [Medline: 18606047]

21. Gronholm PC, Thornicroft G, Laurens KR, Evans-Lacko S. Mental health-related stigma and pathways to care for people at risk of psychotic disorders or experiencing first-episode psychosis: a systematic review. Psychol Med 2017 Aug;47(11):1867-1879. [doi: 10.1017/S0033291717000344] [Medline: 28196549]

22. Nielsen total audience report, Q1 2018. The Nielsen Company (US), LLC. 2018. URL: https://www.nielsen.com/wp-content/ uploads/sites/3/2019/04/q1-2018-total-audience-report.pdf [accessed 2020-08-01]

23. Fox S, Duggan M. Pew Research Center. 2013. URL: https://www.pewresearch.org/internet/2013/01/15/health-online-2013/ [accessed 2020-08-01]

24. Young AS, Cohen AN, Niv N, Nowlin-Finch N, Oberman RS, Olmos-Ochoa TT, et al. Mobile phone and smartphone use by people with serious mental illness. Psychiatr Serv 2020 Mar 01;71(3):280-283. [doi: 10.1176/appi.ps.201900203] [Medline: 31744429 ]

25. Firth J, Cotter J, Torous J, Bucci S, Firth JA, Yung AR. Mobile phone ownership and endorsement of "mHealth" among people with psychosis: a meta-analysis of cross-sectional studies. Schizophr Bull 2016 Mar;42(2):448-455. [doi: 10.1093/schbul/sbv132] [Medline: 26400871]

26. Gay K, Torous J, Joseph A, Pandya A, Duckworth K. Digital technology use among individuals with schizophrenia: results of an online survey. JMIR Ment Health 2016;3(2):e15 [FREE Full text] [doi: 10.2196/mental.5379] [Medline: 27146094]

27. Niendam TA, Tully LM, Iosif A, Kumar D, Nye KE, Denton JC, et al. Enhancing early psychosis treatment using smartphone technology: a longitudinal feasibility and validity study. J Psychiatr Res 2018 Jan;96:239-246. [doi: 10.1016/j.jpsychires.2017.10.017] [Medline: 29126059]

28. Kumar D, Tully LM, Iosif A, Zakskorn LN, Nye KE, Zia A, et al. A mobile health platform for clinical monitoring in early psychosis: implementation in community-based outpatient early psychosis care. JMIR Ment Health 2018 Feb 27;5(1):e15 [FREE Full text] [doi: 10.2196/mental.8551] [Medline: 29487044]

29. Ben-Zeev D, Kaiser SM, Brenner CJ, Begale M, Duffecy J, Mohr DC. Development and usability testing of FOCUS: a smartphone system for self-management of schizophrenia. Psychiatr Rehabil J 2013 Dec;36(4):289-296 [FREE Full text] [doi: 10.1037/prj0000019] [Medline: 24015913]

30. Alvarez-Jimenez M, Bendall S, Lederman R, Wadley G, Chinnery G, Vargas S, et al. On the HORYZON: moderated online social therapy for long-term recovery in first episode psychosis. Schizophr Res 2013 Jan;143(1):143-149. [doi:

10.1016/j.schres.2012.10.009] [Medline: 23146146]

31. Bucci S, Barrowclough C, Ainsworth J, Machin M, Morris R, Berry K, et al. Actissist: proof-of-concept trial of a theory-driven digital intervention for psychosis. Schizophr Bull 2018 Sep;44(5):1070-1080. [doi: 10.1093/schbul/sby032] [Medline: 29566206]

32. Schlosser D, Campellone T, Kim D, Truong B, Vergani S, Ward C, et al. Feasibility of PRIME: a cognitive neuroscience-informed mobile app intervention to enhance motivated behavior and improve quality of life in recent onset schizophrenia. JMIR Res Protoc 2016 Apr 28;5(2):e77 [FREE Full text] [doi: 10.2196/resprot.5450] [Medline: 27125771]

33. Schlosser DA, Campellone TR, Truong B, Etter K, Vergani S, Komaiko K, et al. Efficacy of PRIME, a mobile app intervention designed to improve motivation in young people with schizophrenia. Schizophr Bull 2018 Dec 20;44(5):1010-1020. [doi: 10.1093/schbul/sby078] [Medline: 29939367]

34. King R, Bambling M, Lloyd C, Gomurra R, Smith S, Reid W, et al. Online counselling: the motives and experiences of young people who choose the internet instead of face to face or telephone counselling. Couns Psychother Res 2006 Sep;6(3):169-174. [doi: 10.1080/14733140600848179]

35. Morgan AJ, Jorm AF, Mackinnon AJ. Internet-based recruitment to a depression prevention intervention: lessons from the Mood Memos study. J Med Internet Res 2013;15(2):e31 [FREE Full text] [doi: 10.2196/jmir.2262] [Medline: 23403043]

36. Wise T, Arnone D, Marwood L, Zahn R, Lythe K, Young A. Recruiting for research studies using online public advertisements examples from research in affective disorders. Neuropsychiatr Dis Treat 2016 Feb:279-285. [doi: 10.2147/ndt.s90941]

37. Liu NH, Contreras O, Muñoz RF, Leykin Y. Assessing suicide attempts and depression among Chinese speakers over the internet. Crisis 2014 Sep 01;35(5):322-329 [FREE Full text] [doi: 10.1027/0227-5910/a000261] [Medline: 25115490]

38. Hauser DJ, Schwarz N. Attentive Turkers: MTurk participants perform better on online attention checks than do subject pool participants. Behav Res Methods 2016 Mar 12;48(1):400-407. [doi: 10.3758/s13428-015-0578-z] [Medline: 25761395]

39. Casler K, Bickel L, Hackett E. Separate but equal? A comparison of participants and data gathered via Amazon's MTurk, social media, and face-to-face behavioral testing. Comp Hum Beh 2013 Nov;29(6):2156-2160. [doi: 10.1016/j.chb.2013.05.009]

40. Huff C, Tingley D. "Who are these people?" Evaluating the demographic characteristics and political preferences of MTurk survey respondents. Res Polit 2015 Sep 10;2(3):1-12. [doi: 10.1177/2053168015604648]

41. Downs J, Holbrook M, Sheng S, Cranor L. Are your participants gaming the system?: screening mechanical turk workers. In: Proceedings of the SIGCHI Conference on Human Factors in Computing Systems. 2010 Apr Presented at: CHI '10: CHI Conference on Human Factors in Computing Systems; April, 2010; Atlanta Georgia USA p. 2399-2402. [doi: $\underline{10.1145 / 1753326.1753688}$ ] 
42. Ben-Zeev D, Buck B, Chander A, Brian R, Wang W, Atkins D, et al. Mobile RDoC: using smartphones to understand the relationship between auditory verbal hallucinations and need for care. Schizophr Bull Open 2020 Jan;1(1):sgaa060 [FREE Full text] [doi: 10.1093/schizbullopen/sgaa060] [Medline: 33937774]

43. Crosier BS, Brian RM, Ben-Zeev D. Using Facebook to reach people who experience auditory hallucinations. J Med Internet Res 2016 Jun 14;18(6):e160 [FREE Full text] [doi: 10.2196/jmir.5420] [Medline: 27302017]

44. Population estimates show aging across race groups differs. Public Information Office, United States Census Bureau. 2019 Jun 20. URL: https://www.census.gov/newsroom/press-releases/2019/estimates-characteristics.html [accessed 2020-08-01]

45. ACS demographic and housing estimates. United States Census Bureau. 2019. URL: https://data.census.gov/cedsci/ table?q=demographics\%20and\%20housing\%20estimates\&tid=ACSDP1Y2018.DP05 [accessed 2020-08-01]

46. Smith TW, Davern M, Freese J, Morgan S. General social surveys, 1972-2018. NORC Univ Chicago. URL: https:/ /gssdataexplorer.norc.org/trends/Gender \& Marriage?measure=sexornt [accessed 2020-08-01]

47. Flores A, Herman J, Gates G, Brown T. How many adults identify as transgender in the United States? Williams Institute, UCLA School of Law. 2016 Jun. URL: https://williamsinstitute.law.ucla.edu/publications/trans-adults-united-states/ [accessed 2020-08-01]

48. Henry M, Bishop K, de Sousa T, Shivji A, Watt R. The 2017 Annual Homeless Assessment Report (AHAR) to Congress. The U.S. Department of Housing and Urban Development. 2018 Oct. URL: https://www.huduser.gov/portal/sites/default/ files/pdf/2017-AHAR-Part-2.pdf [accessed 2020-08-01]

49. Birnbaum ML, Garrett C, Baumel A, Scovel M, Rizvi AF, Muscat W, et al. Using digital media advertising in early psychosis intervention. Psychiatr Serv 2017 Nov 01;68(11):1144-1149. [doi: 10.1176/appi.ps.201600571] [Medline: 28712355]

50. Addington J, Epstein I, Reynolds A, Furimsky I, Rudy L, Mancini B, et al. Early detection of psychosis: finding those at clinical high risk. Early Interv Psychiatry 2008 Aug;2(3):147-153. [doi: 10.1111/j.1751-7893.2008.00078.x]

51. Sadler GR, Lee H, Lim RS, Fullerton J. Recruitment of hard-to-reach population subgroups via adaptations of the snowball sampling strategy. Nurs Health Sci 2010 Sep 01;12(3):369-374 [FREE Full text] [doi: 10.1111/j.1442-2018.2010.00541.x] [Medline: 20727089]

52. Fenner Y, Garland SM, Moore EE, Jayasinghe Y, Fletcher A, Tabrizi SN, et al. Web-based recruiting for health research using a social networking site: an exploratory study. J Med Internet Res 2012 Feb;14(1):e20 [FREE Full text] [doi: 10.2196/jmir.1978] [Medline: 22297093]

53. Graham AL, Milner P, Saul JE, Pfaff L. Online advertising as a public health and recruitment tool: comparison of different media campaigns to increase demand for smoking cessation interventions. J Med Internet Res 2008 Dec 15;10(5):e50 [FREE Full text] [doi: 10.2196/jmir.1001] [Medline: 19073542]

54. Seltzer ED, Stolley MR, Mensah EK, Sharp LK. Social networking site usage among childhood cancer survivors - a potential tool for research recruitment? J Cancer Surviv 2014 Sep 16;8(3):349-354 [FREE Full text] [doi: 10.1007/s11764-014-0348-4] [Medline: 24532046]

55. Birnbaum ML, Rizvi AF, Confino J, Correll CU, Kane JM. Role of social media and the internet in pathways to care for adolescents and young adults with psychotic disorders and non-psychotic mood disorders. Early Interv Psychiatry 2017 Dec;11(4):290-295. [doi: 10.1111/eip.12237] [Medline: 25808317]

56. Ben-Zeev D. The digital mental health genie is out of the bottle. Psychiatr Serv 2020 Dec 01;71(12):1212-1213. [doi: 10.1176/appi.ps.202000306] [Medline: 32576123]

\section{Abbreviations \\ AVH: auditory verbal hallucinations \\ IP: internet protocol \\ SSD: schizophrenia spectrum disorder}

Edited by $G$ Eysenbach; submitted 01.08.20; peer-reviewed by A Wright, C Arnold, T Campellone; comments to author 29.09.20;
revised version received 09.10.20; accepted 12.04.21; published 03.06.21
Please cite as:
Buck B, Chander A, Brian RM, Wang W, Campbell AT, Ben-Zeev D
Expanding the Reach of Research: Quantitative Evaluation of a Web-Based Approach for Remote Recruitment of People Who Hear
Voices
JMIR Form Res $2021 ; 5(6):$ :e23118
URL: $\underline{\text { https://formative.jmir.org/2021/6/e23118 }}$
doi: $\underline{10.2196 / 23118}$
PMID:


CBenjamin Buck, Ayesha Chander, Rachel M Brian, Weichen Wang, Andrew T Campbell, Dror Ben-Zeev. Originally published in JMIR Formative Research (https://formative.jmir.org), 03.06.2021. This is an open-access article distributed under the terms of the Creative Commons Attribution License (https://creativecommons.org/licenses/by/4.0/), which permits unrestricted use, distribution, and reproduction in any medium, provided the original work, first published in JMIR Formative Research, is properly cited. The complete bibliographic information, a link to the original publication on https://formative.jmir.org, as well as this copyright and license information must be included. 